\title{
How to Efficiently Promote Transition Metal Oxides by Alkali Towards Catalytic Soot Oxidation
}

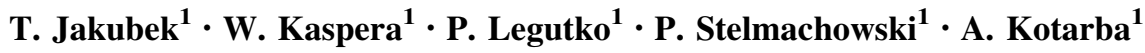

Published online: 5 May 2016

(c) The Author(s) 2016. This article is published with open access at Springerlink.com

\begin{abstract}
The effect of surface and bulk potassium promotion on the transition metal oxides (Mn, Fe, Co) catalytic activity in catalytic soot oxidation was investigated. The surface promotion was obtained via incipient wetness impregnation, whereas the bulk promotion-nanostructuration - was obtained via wet chemical synthesis or solid state reaction leading to mixed oxide materials. The introduction of potassium into the transition metal oxide matrix results in the formation of tunneled or layered structures, which enable high potassium mobility. The structure of the obtained materials was verified by powder $\mathrm{X}$-ray diffraction and Raman spectroscopy and the catalytic activity in soot oxidation was determined by TPO-QMS and TGA. It was found that the surface promotion does not alter the metal oxide structure and leads to either enhancement ( $\mathrm{Mn}, \mathrm{Fe})$ or deterioration (Co) of the catalytic activity. Simultaneously, the catalytic activity in soot combustion of the potassium structured oxides is strongly enhanced. The most active, cobalt oxide based catalyst significantly lowers the temperature of $50 \%$ of soot conversion by $\sim 350{ }^{\circ} \mathrm{C}$ comparing to the non-catalyzed process. The study allows for the establishment of rational guidelines for designing robust materials for DPF applications based on ternary metal oxides.
\end{abstract}

Keywords Soot oxidation - Metal oxide - Catalyst · Transition metal oxide $\cdot$ Potassium promotion

A. Kotarba

kotarba@chemia.uj.edu.pl

1 Faculty of Chemistry, Jagiellonian University in Kraków, ul. Ingardena 3, 30-060 Kraków, Poland

\section{Introduction}

The most common way to produce energy from carbon materials is by their combustion. Among many products obtained during this process, soot is considered as one of the most harmful [1]. It consists mostly of an amorphous carbon, some of its allotropes (graphite, fullerene), unsaturated hydrocarbons and many impurities, depending on the fuel and the combustion process itself [2]. Due to the nanometric size of its particles and cancero- and mutagenic properties [3], soot is dangerous for human health. A negative effect on global warming has also been reported [4].

Several solutions for soot emission reduction have been proposed so far. Reactor and engine modifications are very often expensive or technologically inapplicable. The idea of fuel additives has also been presented [5]. A combination of a diesel particulate filter (DPF) system with the catalytic combustion of soot seems to be the most promising and effective solution [6-8]. As such systems use catalysts based on platinum or palladium the increasing price of these noble metals creates demand for a cheaper alternative.

Many active phases based on metals and metal oxides for catalytic soot combustion have been reported. Ceriabased catalysts are the most widely investigated [9-11]. Some simple transition metals or oxides also exhibit good catalytic activity and stability [12]. The most promising materials in terms of activity, price and environmental friendliness are based on perovskites [13, 14] and spinels $[15,16]$. The research presented in this paper is focused on the catalytic activity of manganese, iron and cobalt spinels in soot combustion as they are commonly known as the catalysts for many oxidation reactions, for example methane [17], carbon oxide [18] or aromatic compounds [19]. 
Enhancing the catalytic activity of such materials by alkali addition has been frequently reported [20-24]. Doping occurs mainly in one of two ways: alkali cations can be dispersed on the surface $[25,26]$ or intercalated into the structure [20]. Surface modifications are believed to have a number of effects. Firstly, they result in the modification of the electrodonor properties of the surface [15], which may lead to the formation of active forms of oxygen by means of the electron transfer. Secondly, the formation of low melting point compounds or superficial carbonate intermediates may improve soot-catalyst contact [9]. Intercalation very often leads to layered or tunneled structures (nanostructuration) enabling very high potassium cation mobility [20, 21] but can also change the catalytic activity leaving the structure unaffected, i.e. intercalation in glass [27] or substitution of other metals [28]. The temperature of diesel exhaust systems varies from 250 to $400{ }^{\circ} \mathrm{C}$, but during the regeneration step it reaches up to $700{ }^{\circ} \mathrm{C}[29,30]$ and, in that temperature, the aforementioned processes take place.

Previous research in this area revealed, that the calcination of a spinel wet impregnated with alkali can lead to promotion of both natures $[20,21]$. The aim of this work was to perform systematic research concerning surface and bulk promotion in order to compare their effect for manganese, iron and cobalt spinels. For such purpose not only surface promoted spinels $\left(\mathrm{K}-\mathrm{Mn}_{3} \mathrm{O}_{4}, \mathrm{~K}-\mathrm{Fe}_{3} \mathrm{O}_{4}, \mathrm{~K}-\mathrm{Co}_{3} \mathrm{O}_{4}\right)$ were prepared, but nanostructured phases $\left(\mathrm{KMn}_{4} \mathrm{O}_{8}\right.$, $\mathrm{KMn}_{8} \mathrm{O}_{16}, \mathrm{KFeO}_{2}, \mathrm{~K}_{2} \mathrm{Fe}_{22} \mathrm{O}_{34}, \mathrm{KCo}_{2} \mathrm{O}_{4}, \mathrm{KCo}_{4} \mathrm{O}_{8}$ ) were synthesized as well.

\section{Experimental}

\subsection{Catalyst Preparation}

Surface promotion: the surface doped catalysts were prepared by wet impregnation of $1 \mathrm{~g}$ of the investigated spinels $\left(\mathrm{Mn}_{3} \mathrm{O}_{4}, \mathrm{Fe}_{3} \mathrm{O}_{4}\right.$-Aldrich, $\mathrm{Co}_{3} \mathrm{O}_{4}$-Fluka $)$ with a potassium carbonate (POCh) to achieve optimal alkali loading corresponding to theoretical 0.5 monolayer, as described in [15]. Impregnated spinels were dried at $100{ }^{\circ} \mathrm{C}$ for $1 \mathrm{~h}$, and subsequently calcined at $400{ }^{\circ} \mathrm{C}$ for $4 \mathrm{~h}$. The temperature was optimal for potassium cations to disperse equally on the surface, and low enough not to change the structure or surface area of investigated spinels.

Birnessite, $\mathrm{KMn}_{4} \mathrm{O}_{8}$ : a glucose (POCh) solution containing $14 \mathrm{~g}$ of glucose was mixed with a potassium permanganate (POCh) solution containing $8.17 \mathrm{~g}$ in order to achieve a molar ratio of 1.5:1. The formed solution was mixed at room temperature until a brown xero-gel was formed. The excess water was filtered and the gel was dried $\left(100{ }^{\circ} \mathrm{C}\right)$ overnight. The obtained solid was calcined at $450{ }^{\circ} \mathrm{C}$ for $2 \mathrm{~h} \mathrm{[31].}$
Cryptomelane, $\mathrm{KMn}_{8} \mathrm{O}_{16}: 11 \mathrm{~g}$ of manganese acetate (Sigma-Aldrich) was dissolved in $40 \mathrm{ml}$ of water, to which $5 \mathrm{ml}$ of glacial acetic acid was added to adjust the $\mathrm{pH}$. The solution was heated to boiling under reflux and maintained for $45 \mathrm{~min}$. $6.5 \mathrm{~g}$ of potassium permanganate (POCh), dissolved in $150 \mathrm{ml}$ of water, was then added. The mixture was stirred and heated for $24 \mathrm{~h}$. The obtained solid phase was filtered and washed with distilled water until neutral $\mathrm{pH}$, dried at $80{ }^{\circ} \mathrm{C}$ and calcined at $450{ }^{\circ} \mathrm{C}$ for $2 \mathrm{~h}$ [31].

Monoferrite, $\mathrm{KFeO}_{2}: 2.83 \mathrm{~g}$ of potassium carbonate (POCh) and 2.985 of hematite $\left(\alpha-\mathrm{Fe}_{2} \mathrm{O}_{3}\right.$-Merck) were ground together for $30 \mathrm{~min}$ in an agate mortar. The powder was pressed into a pellet under $6 \mathrm{MPa}$ and placed in a ceramic crucible, which was heated to $800{ }^{\circ} \mathrm{C}$ and kept at this temperature for $1 \mathrm{~h}$. Once the furnace had cooled the crucible was removed. The pellet was then ground for $15 \mathrm{~min}$, repressed and heated. The temperature of $800{ }^{\circ} \mathrm{C}$ was maintained for $20 \mathrm{~h}$. The sample was then removed once the furnace had cooled [21].

Betaferrite, $\mathrm{K}_{2} \mathrm{Fe}_{22} \mathrm{O}_{34}$ : $1.45 \mathrm{~g}$ of potassium carbonate (POCh) and $8.70 \mathrm{~g}$ of hematite $\left(\alpha-\mathrm{Fe}_{2} \mathrm{O}_{3}\right.$-Merck) were ground for $30 \mathrm{~min}$ in an agate mortar. The powder was pressed into a pellet, placed in a ceramic crucible and heated to $900{ }^{\circ} \mathrm{C}$ for $1 \mathrm{~h}$. The pellet was then ground for $15 \mathrm{~min}$ and heated to $1200{ }^{\circ} \mathrm{C}$ for $5 \mathrm{~h} \mathrm{[21].}$

Cobaltate I, $\mathrm{KCo}_{4} \mathrm{O}_{8}: 2.13 \mathrm{~g}$ of cobalt(II,III) oxide (Fluka) was ground with $1.1 \mathrm{~g}$ of potassium hydroxide (POCh). The solid mixture was then calcined at $700{ }^{\circ} \mathrm{C}$ for $12 \mathrm{~h}$. The oven was slowly cooled to $300{ }^{\circ} \mathrm{C}$ upon which the sample was removed and washed with distilled water. Recipe was based on [32].

Cobaltate II, $\mathrm{KCo}_{2} \mathrm{O}_{4}: 1.51 \mathrm{~g}$ of the sample from the previous synthesis was then reground with $0.75 \mathrm{~g}$ of potassium hydroxide ( $\mathrm{POCh}$ ), pressed into a pellet and placed in an oven preheated to $700{ }^{\circ} \mathrm{C}$ for $19.5 \mathrm{~h}$. Upon cooling the sample was ground and washed with distilled water [32].

Different preparation methods for the investigated materials result from the limited possibilities of synthesis protocols. The main focus of this study was to elucidate the scale of the potassium promotional effect on the activity of series of transition metal oxides with the emphasis on the alkali promoter location. Therefore, to obtain various nanostructured phases and surface promoted transition metal oxides different preparation methods were applied. Limited diversity of investigated nanocrystals shapes are a direct consequence of the limited possibilities of synthesis protocols. However, we are aware that morphology is an important factor influencing catalysts activity [33, 34]. In our case nanoneedle type crystals of cryptomelane exhibit high soot oxidation activity related to the electronic excitation of the potassium promoter at elevated temperatures [35]. 
The micrometric cerium(IV) oxide used as a reference for the catalytic tests was commercially purchased at Merck.

\subsection{Physicochemical Characterization}

The XRD patterns were recorded by a Rigaku MiniFlex powder diffractometer with $\mathrm{Cu} \mathrm{K} \alpha$ radiation at $10 \mathrm{~mA}$ and $10 \mathrm{kV}, 2 \theta$ step scans of $0.02^{\circ}$ and a counting time of $1 \mathrm{~s}$ per step. The micro-Raman spectra were recorded in ambient conditions using a RenishawInVia spectrometer equipped with a Leica DMLM confocal microscope and a CCD detector, with an excitation wavelength of $785 \mathrm{~nm}$. The laser power at the sample position was $1.5 \mathrm{~mW}(0.5 \mathrm{of}$ total power) with a magnification of $\times 20$. The Raman scattered light was collected in the spectral range of 200-850 $\mathrm{cm}^{-1}$. At least six scans, $10 \mathrm{~s}$ each, were accumulated to ensure a sufficient signal to noise ratio. Composition of synthesized materials was determined by X-ray fluorescence spectroscopy on ARL Quant'X spectrometer. The BET surface area of the catalysts was determined by $\mathrm{N}_{2}$ adsorption at $-196{ }^{\circ} \mathrm{C}$ in an automatic volumetric system (Autosorb-6, Quantachrome).

\subsection{Reactivity Tests}

Catalytic activity in soot combustion reaction of catalysts was determined by temperature programmed oxidation (TPO-QMS and TGA). For the TPO tests a quartz fixed-bed reactor was heated $\left(10{ }^{\circ} \mathrm{C} / \mathrm{min}\right)$ from $\mathrm{RT}$ to $900{ }^{\circ} \mathrm{C}$ in an oxygen atmosphere $\left(5 \% \mathrm{O}_{2}\right.$ in $\left.\mathrm{He}\right)$ at a $60 \mathrm{ml} / \mathrm{min}$ flow. The samples for the soot combustion tests were prepared by weighing $0.05 \mathrm{~g}$ of soot (Degussa-Printex80) and the catalyst in an 1:8 ratio and then ground in a mortar for $10 \mathrm{~min}$ (tight contact). The changes in the gas composition upon the soot oxidation reaction were monitored by a quadrupole mass spectrometer (spectrometer (SRS RGA200, lines for $\mathrm{m} / \mathrm{z}=46\left(\mathrm{NO}_{2}\right), 44\left(\mathrm{CO}_{2}\right), 32\left(\mathrm{O}_{2}\right), 30(\mathrm{NO}), 28(\mathrm{CO}), 18$ $\left.\left(\mathrm{H}_{2} \mathrm{O}\right)\right)$. For all the investigated catalysts the observed selectivity of the catalysts towards $\mathrm{CO}_{2}$ was complete, with the only measured signals of $\mathrm{CO}$ originating from the fragmentation of $\mathrm{CO}_{2}$ in the quadrupole ionizer. The reproducibility of the catalytic activity tests was confirmed by at least three runs on the same material, while the stability was assessed by $3-5$ consecutive runs on the same sample adding a new portion of soot after each complete burning e.g., $\Delta T_{50} \%$ for some samples (K-ferrites) do not change within the experimental limit, whereas for K-manganates catalysts a slight deterioration was observed depending on the maximum temperature, e.g. for heating up to $700{ }^{\circ} \mathrm{C}$ the observed shift after three runs in $\Delta T_{50} \%$ reached $40{ }^{\circ} \mathrm{C}$.

The best catalysts based on each transition metal oxide were further analyzed by using a thermogravimetric analyses (TGA) method on a Mettler Toledo TGA/DSC1 apparatus. The experiments were conducted by placing $\sim 7 \mathrm{mg}$ of the samples mixed with soot in tight contact, as mentioned above for TPO-QMS, in a alumina crucible and heated in the gas flow (air $40 \mathrm{ml} / \mathrm{min}$ + purge Ar $20 \mathrm{ml} /$ min) at a temperature ramp of $10{ }^{\circ} \mathrm{C} / \mathrm{min}$ in the range from room temperature to $800{ }^{\circ} \mathrm{C}$.

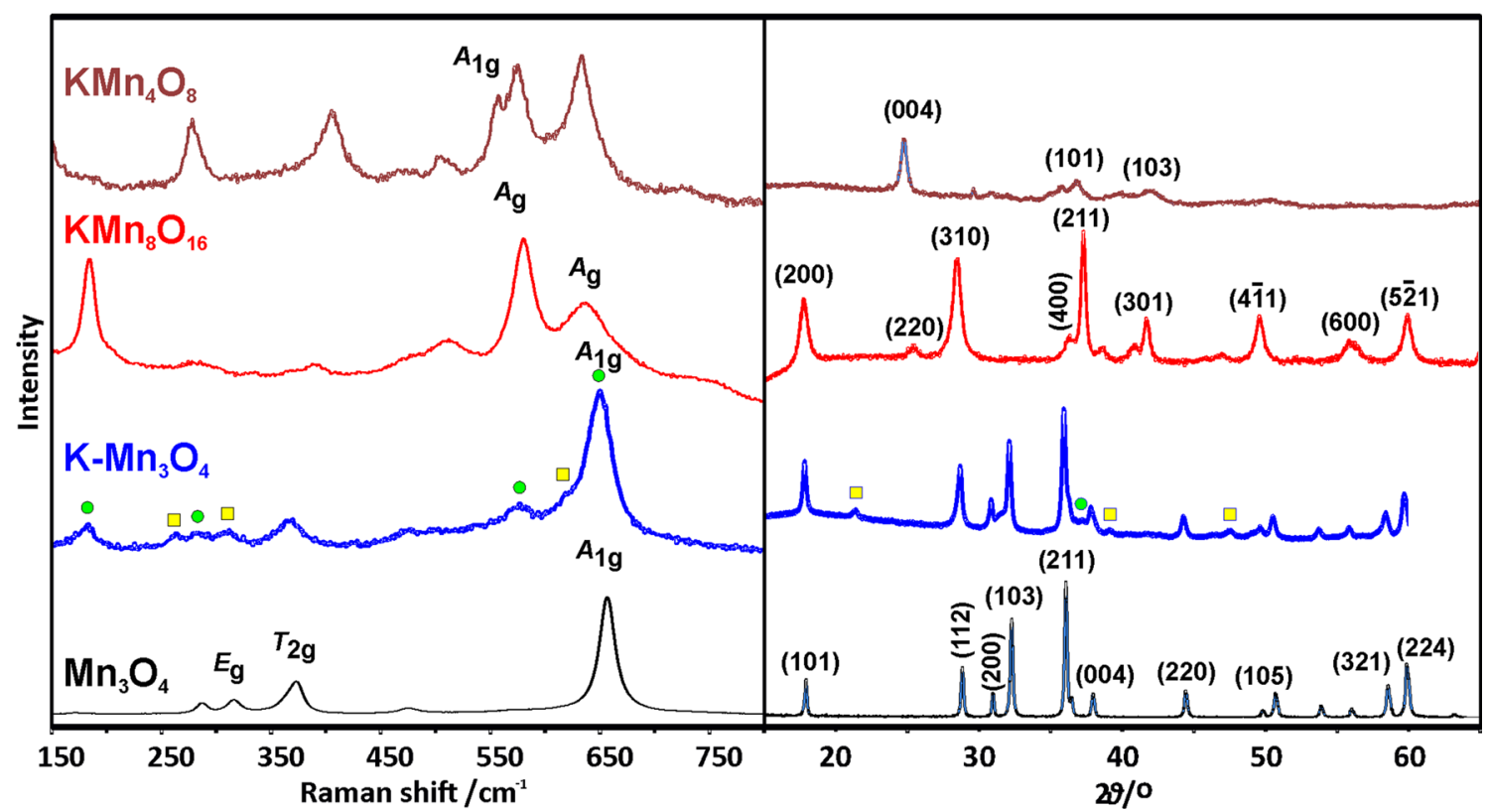

Fig. 1 Raman spectra and XRD patterns of manganese-based catalysts 


\section{Results and Discussion}

Diffraction patterns obtained for the manganese-based phases (Fig. 1) show that surface promotion of $\mathrm{Mn}_{3} \mathrm{O}_{4}$ with potassium leads to formation of small amounts of $\mathrm{MnO}_{2}$ (yellow squares). The patterns obtained for bulk-doped manganese oxides confirm the structures of tunneled birnessite and layered cryptomelane $\left(\mathrm{KMn}_{4} \mathrm{O}_{8}\right.$ and $\mathrm{KMn}_{8} \mathrm{O}_{16}$, respectively). Raman spectra of the investigated samples confirmed the presence of $\mathrm{MnO}_{2}$ and cryptomelane on the surface-doped catalysts by the presence of their characteristic peaks $[36,37]$. The Raman spectra of bulk-doped manganese catalysts depict characteristic peaks of the nanostructured phases [38], confirming the XRD results.

Diffraction patterns obtained for iron-based samples are shown in Fig. 2. The diffractogram of the surface-doped iron spinel corresponds mostly to the pattern of the reference iron spinel. The observed small reflexes (orange

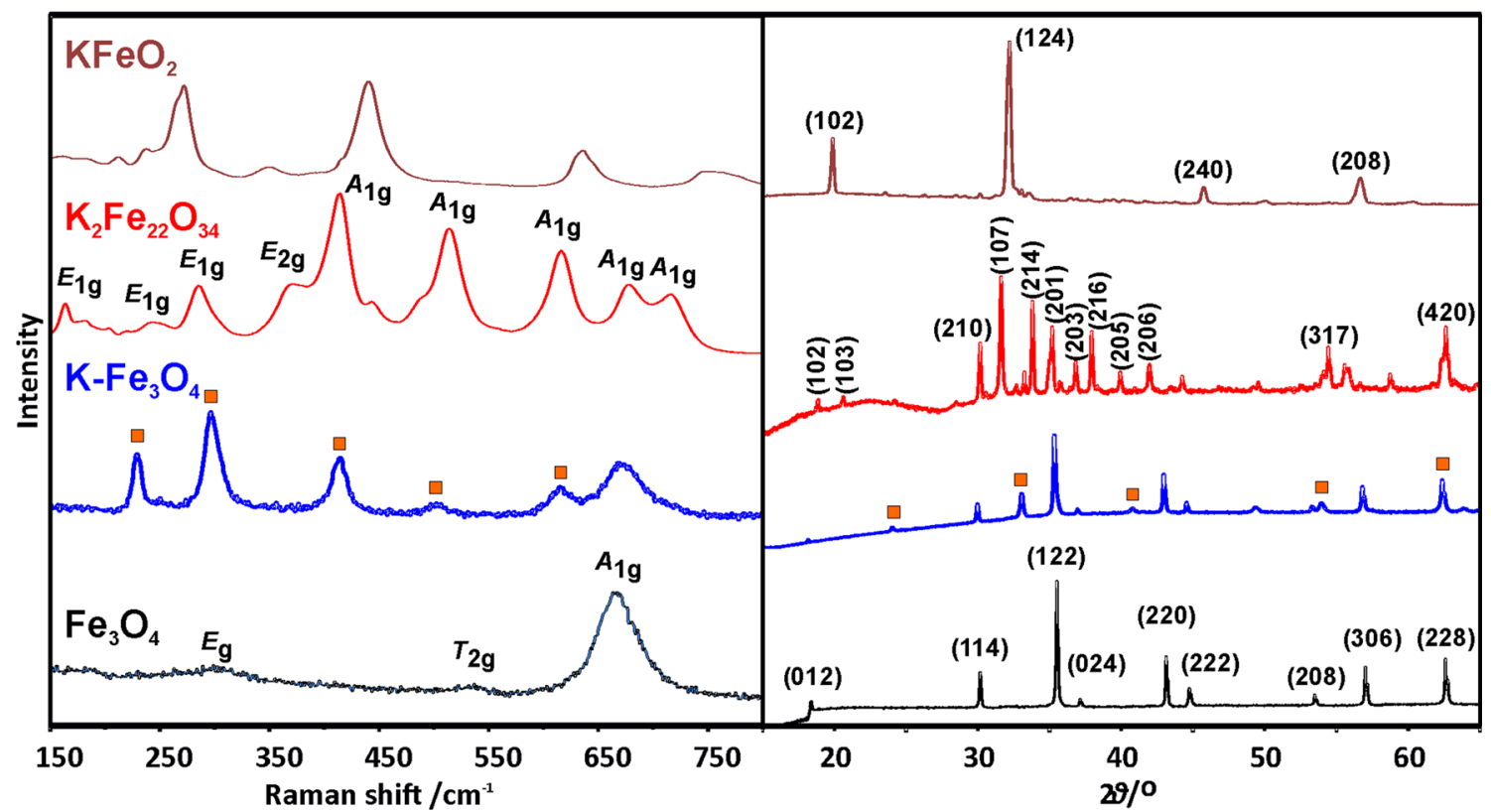

Fig. 2 Raman spectra and XRD patterns of iron-based catalysts

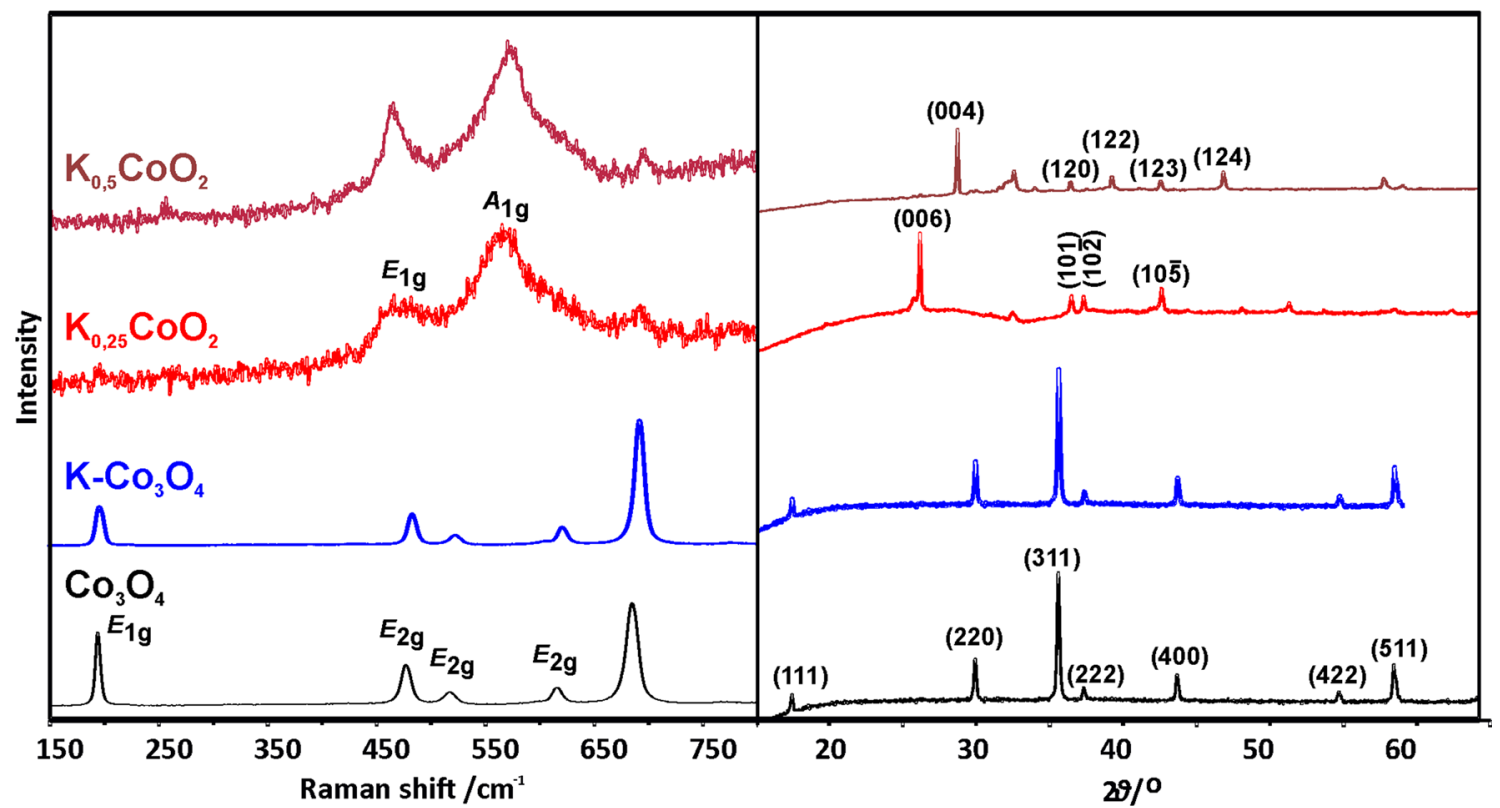

Fig. 3 Raman spectra and XRD patterns of cobalt-based catalysts 
squares) belongs to the hematite phase, resulting from the surface oxidation of $\mathrm{Fe}_{3} \mathrm{O}_{4}$. As in the case of the Mn-based catalysts, the formation of both tunneled (monoferrite$\mathrm{KFeO}_{2}$ ) and layered (betaferrite- $-\mathrm{K}_{2} \mathrm{Fe}_{22} \mathrm{O}_{34}$ ) structures was confirmed. The characteristic peaks of hematite, apart from that of the iron spinel, in the Raman spectra of the surface-doped catalyst confirmed the XRD results. References to Raman spectra of the bulk-doped phases are not found in literature, however, the peaks for betaferrite may be assigned to vibrations based on the detailed investigations into the $\mathrm{BaFe}_{12} \mathrm{O}_{19}$ ferrite [39].

Diffractograms of the cobalt-based catalysts are shown in Fig. 3. The diffraction pattern of $\mathrm{K} / \mathrm{Co}_{3} \mathrm{O}_{4}$ confirms, that surface alkali promotion leaves the spinel structure unaffected. Intercalation of potassium cations into the cobalt oxide structure leads to formation of layers of cobalt oxide blocks between which the $\mathrm{K}^{+}$ions are located, which is confirmed by the corresponding diffractograms. The Raman spectra of the bulk and surface-promoted catalysts show no additional peaks other than those characteristic for the investigated phases [40, 41]. All the diffraction data were indexed within the adequate space group according to the ICSD database entries $\left(\mathrm{KMn}_{4} \mathrm{O}_{8}-152290, \mathrm{KMn}_{8-}\right.$ $\mathrm{O}_{16}-59159, \mathrm{KFeO}_{2}-94467, \mathrm{~K}_{2} \mathrm{Fe}_{22} \mathrm{O}_{34}-83285, \mathrm{KCo}_{4}$ $\mathrm{O}_{8}-154037, \mathrm{KCo}_{2} \mathrm{O}_{4}-6151$ ).

The BET surface area of the catalysts were in a typical range of $5-35 \mathrm{~m}^{2} / \mathrm{g}$, however, since the most active phases were obtained in high temperature solid state synthesis or were calcined at high temperature they exhibit relatively low surface areas of $5.6\left(\mathrm{KMn}_{4} \mathrm{O}_{8}\right), 5\left(\mathrm{KCo}_{4} \mathrm{O}_{8}\right)$ and 15 $\left(\mathrm{KFeO}_{2}\right) \mathrm{m}^{2} / \mathrm{g}$. It was found that for the investigated catalysts there is no direct correlation between the activity and surface areas. It can be underlined here that for the alkali promoted catalyst, the electronic factor plays a primary role over the number of catalyst-soot contacts, which are proportional to surface area, as shown elsewhere [21]. The low work function of the alkali containing catalyst facilitates the formation of $\mathrm{O}_{2}{ }^{-}$(oxygen activation) [42] via the electron transfer.

The conversion curves obtained from soot combustion activity tests (TPO) are shown in Fig. 4. The figure depicts the conversion of soot over the appropriate transition metal ( $\mathrm{Mn}, \mathrm{Fe}, \mathrm{Co}$ ) catalyst with the unpromoted spinel as reference (curve b), the surface K-doped sample (curve c) and the best bulk K-doped sample (curve a). Curves a thus represent $\mathrm{KMn}_{4} \mathrm{O}_{8}$ (birnessite), $\mathrm{KFeO}_{2}$ (monoferrite) and $\mathrm{KCo}_{4} \mathrm{O}_{8}$ (cobaltate I), respectively. The green-shaded area depicts the temperature range in which soot is combusted by the less active nanostructured oxides for each transition metal i.e. $\mathrm{KMn}_{8} \mathrm{O}_{16}$ (cryptomelane), $\mathrm{K}_{2} \mathrm{Fe}_{22} \mathrm{O}_{34}$ (betaferrite) and $\mathrm{KCo}_{2} \mathrm{O}_{4}$ (cobaltate II). The results obtained for the manganese-based catalysts reveal, that both surface and bulk doping of the manganese spinel with potassium results

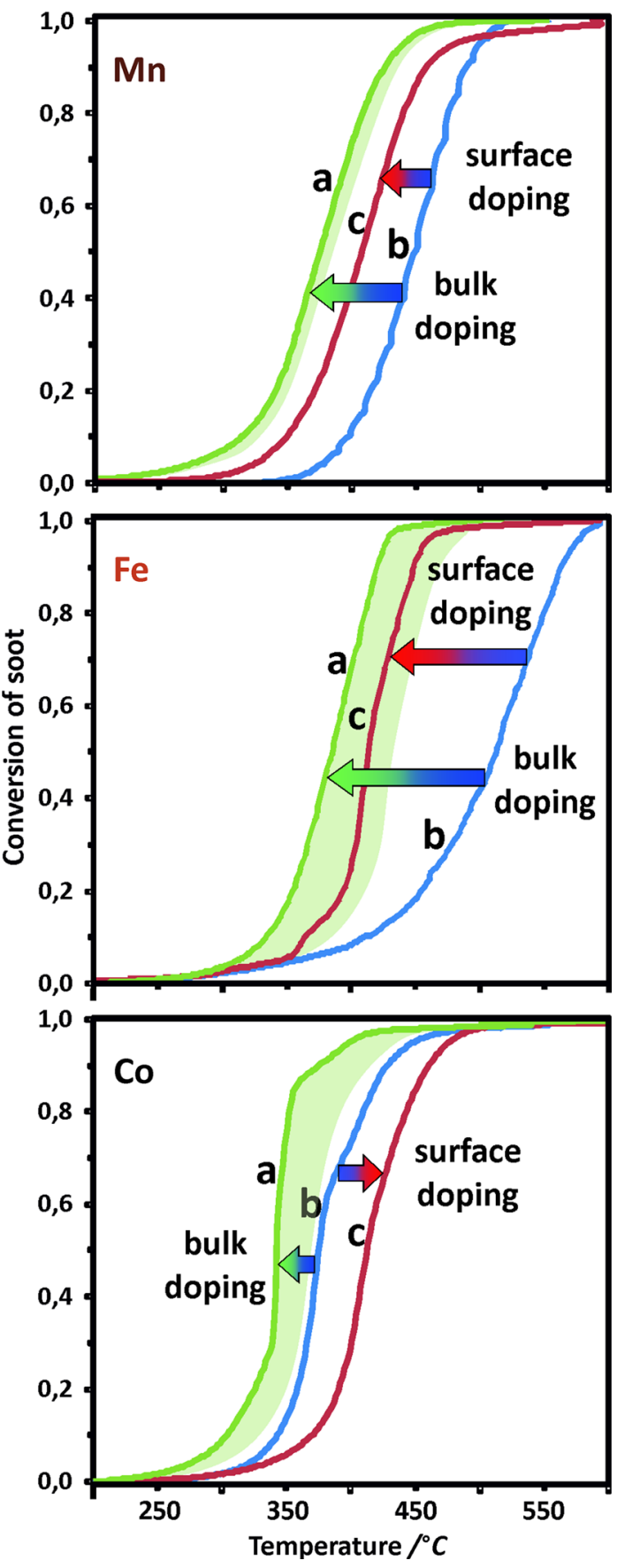

Fig. 4 Effect of potassium doping on catalytic activity of spinels ( $a$ bulk promoted $\left(\mathrm{KMn}_{4} \mathrm{O}_{8}, \mathrm{KFeO}_{2}, \mathrm{KCo}_{4} \mathrm{O}_{8}\right), b$ unpromoted spinel, $c$ surface promoted). Shaded area depicts range of soot combustion conversion curves for the less active nanostructured catalysts

in an enhancement of the catalytic activity. In the first case, the catalytic enhancement is visible even with the formation of the inactive $\mathrm{MnO}_{2}$ as small amounts of active $\mathrm{K}_{\mathrm{x}}$ $\mathrm{Mn}_{\mathrm{y}} \mathrm{O}$ phases are also formed on the surface of the spinel [14]. In the second case, intercalation of potassium into the oxide lattice leads to formation of pure cryptomelane or birnessite structure, resulting in an $\sim 70{ }^{\circ} \mathrm{C}$ shift of the 
Fig. 5 Soot conversion as a function of temperature for the best obtained nanostructured (bulk promoted) $\mathrm{Fe}, \mathrm{Mn}$ and Co-based catalysts in tight contact conditions using TG and TPO

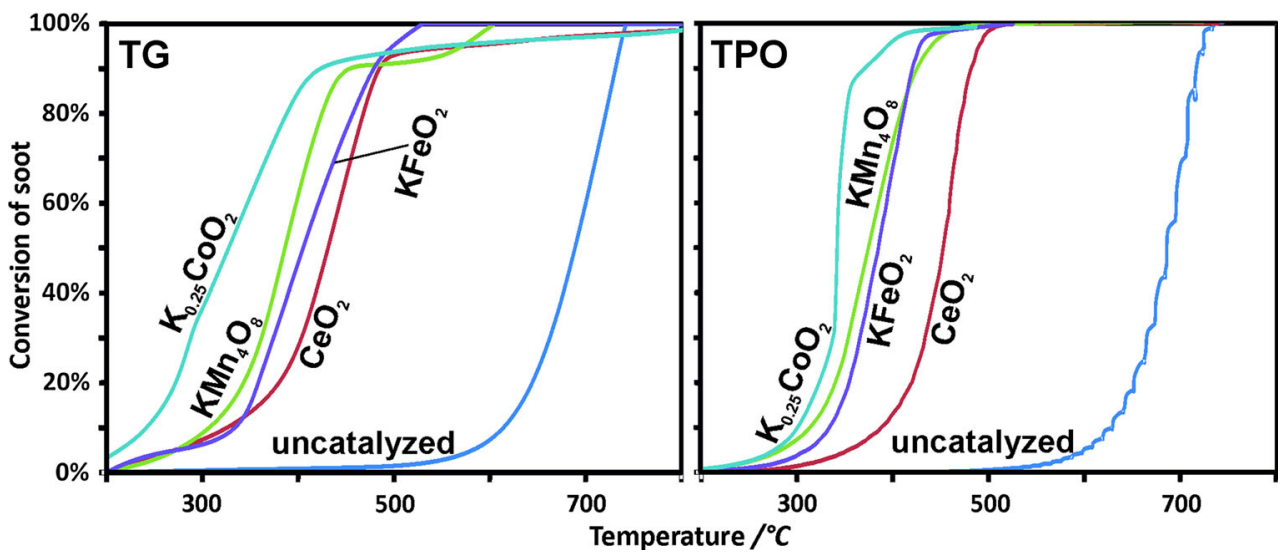

$50 \%$ conversion temperature $\left(T_{50} \%\right)$ comparing to the reference spinel.

Activity tests performed on the iron-based catalysts show that potassium promotion of both natures leads to the important shift of the process temperature into lower values. The strong effect of surface doping can be associated with the lowering of the work function of the material [15], leading to the enhancement of the catalytic activity, possibly due to an increased rate of gas phase oxygen activation [26]. The enhanced activity of the structurally doped iron oxide $\left(\Delta T_{50} \%=100{ }^{\circ} \mathrm{C}\right)$ can be, as in the case of manganese oxide, a result of heightened potassium mobility.

Contrary to the $\mathrm{Mn}_{3} \mathrm{O}_{4}$, and $\mathrm{Fe}_{3} \mathrm{O}_{4}$, surface doping of $\mathrm{Co}_{3} \mathrm{O}_{4}$ with potassium lowers its catalytic activity. The promotion leads not only to the lowering of the work function but also excessively accelerates the recombination of active oxygen species on the surface of the catalyst [18, 43] making them unavailable for the oxidation reaction. Bulk promotion of cobalt oxide results in formation of the most active materials among those investigated $\left(\Delta T_{50 \%}<350{ }^{\circ} \mathrm{C}\right)$ due to the modification of the oxidation states of cobalt as revealed by XPS in [43].

For all the investigated transition metal oxides promotion with potassium, both surface and bulk, leads to work function lowering. While for the manganese and iron-oxide materials it results in the increase of the catalytic activity it is opposite for the surface K-promoted cobalt spinel. Since the activation of oxygen takes place via electron transfer from the surface for all the materials, only in the case of the surface promoted cobalt oxide the surface oxygen recombination rate is more significant than the oxygen activation, leading to a decrease in the activity.

The results of the activity tests of the chosen, most active catalysts performed using TGA are presented in Fig. 5, with the reference cerium(IV) oxide. The results confirm that both testing methods (TPO and TGA) can be used reliably, as the sequence of the catalysts activity remains the same. All three of the nanostructured oxides are more active than the typical cerium(IV) oxide (Merck). Since the reported catalytic data are collected for various conditions (gas phase composition, soot type, soot:catalyst ratio, contact type, analysis method, etc.) the direct comparison is problematic and not useful. The standard ceria material used as a reference allows for the demonstration of the high soot combustion catalytic activity of the investigated catalysts.

Concluding the obtained results allow to elucidate the scale of potassium promotional effect on the activity in soot oxidation of transition metal oxides with the emphasis on the alkali promoter location. The results clearly show that the bulk promotion is superior to the surface one and the sequence of catalytic activity of the most active phase for each of the transition metal is $\mathrm{KCo}_{4} \mathrm{O}_{8}>$ $\mathrm{KMn}_{4} \mathrm{O}_{8}>\mathrm{KFeO}_{2}>\mathrm{CeO}_{2}$.

This laboratory research on powdered samples was used for selection of materials for preparation of CDPFs (Catalytic Diesel Particulate Filters). The most promising catalytic materials (nanostructured ferrites and manganates) were deposited onto SiC monolithic systems, following the protocol described in [44, 45]. The studies in the engine bench are in progress now.

\section{Conclusions}

The research presented in the paper reveals, that the effect of doping spinels with potassium strongly depends on the nature of transition metal. In the case of structural promotion, the formation of tunneled or layered structures, which enable very high potassium mobility, results in a very strong enhancement of the catalytic activity in soot combustion, with the most active, cobalt oxide based catalyst lowering the $T_{50} \%$ of soot combustion by $\sim 350{ }^{\circ} \mathrm{C}$. The study allows for the establishment of rational guidelines for designing robust materials for CDPF applications based on ternary metal oxides. 
Acknowledgments The project was financed by the Polish National Science Center awarded by Decision Number DEC-2011/01/B/ST4/ 00574. The research was carried out with the equipment purchased thanks to the financial support of the European Regional Development Fund in the framework of the Polish Innovation Economy Operational Program (Contract No. POIG.02.01.00-12-023/08). Piotr Legutko received funding for the preparation of his doctoral dissertation from the Polish National Science Center under the doctoral scholarship funding program based on the Decision Number DEC2014/12/T/ST4/00687.

Open Access This article is distributed under the terms of the Creative Commons Attribution 4.0 International License (http://crea tivecommons.org/licenses/by/4.0/), which permits unrestricted use, distribution, and reproduction in any medium, provided you give appropriate credit to the original author(s) and the source, provide a link to the Creative Commons license, and indicate if changes were made.

\section{References}

1. Sydbom A, Blomberg A, Parnia S, Stenfors N, Sandstrom T, Dahlen S-E (2001) Eur Respir J 17:733-746

2. Alander TJA, Leskinen AP, Raunemaa TM, Antanen L (2004) Environ Sci Technol 38:2707-2714

3. Bruske-Hohlfeld I, Mohner M, Ahrens W, Pohlabeln H, Heinrich J, Kreuzer M, Jockel K-H, H-E Wichmann (1999) Am J Ind Med 36:405-414

4. Hansen J, Nazarenko L (2004) Proc Natl Acad Sci USA 101:423-428

5. Wakefield G, Wu X, Gardener M, Park B, Anderson S (2008) Technol Anal Strateg 20:127-136

6. Fino D (2007) Sci Technol Adv Mater 8:93-100

7. Van Setten BAAL, Makkee M, Moulijn J (2001) Catal Rev 43:489-564

8. Su C, McGinn P (2009) Conference Proceedings - 2009 AIChE Annual Meeting, 09AIChE

9. Hernandez-Gimenez AM, Castello DL, Bueno-Lopez A (2014) Chem Pap 68:1154-1168

10. Katta L, Sudarsanam P, Thrimurthulu G, Reddy BM (2010) Appl Catal B 101:101-108

11. Atribak I, Bueno-Lopez A, Garcia-Garcia A (2008) Catal Commun 9:250-255

12. Zawadzki M, Walerczyk W, López-Suárez FE, Illán-Gómez MJ, Bueno-López A (2011) Catal Commun 12:1238-1241

13. Teraoka Y, Nakano K, Shangguan W, Kagawa S (1996) Catal Today 27:107-113

14. Fino D, Russo N, Cauda E, Saracco G, Specchia V (2006) Catal Today 114:31-39

15. Legutko P, Kaspera W, Jakubek T, Stelmachowski P, Kotarba A (2013) Top Catal 56:745-749

16. Fino D, Russo N, Saracco G, Specchia V (2006) J Catal 242:38-47

17. Xu X, Han H, Liu J, Liu W, Wang X (2014) J Rare Earth 32:159-169
18. Liu H, Patzke GR (2014) Ceram Eng Sci Proc 34:75-86

19. Mountapmbeme Kouotou P, Vieker H, Tian Z Y, Tchoua Ngamou P H, El Kasmi A, Beyer A, Golzhauser A, Kohse-Hoinghaus K (2014) Catal Sci Technol 4:3359-3367

20. Legutko P, Jakubek T, Kaspera W, Stelmachowski P, Sojka Z, Kotarba A (2014) Catal Commun 43:34-37

21. Legutko P, Stelmachowski P, Trębala M, Sojka Z, Kotarba A (2013) Top Catal 56:489-492

22. Ogura M, Kimura R, Ushiyama H, Nikaido F, Yamashita K, Okubo T (2014) ChemCatChem 6:479-484

23. Stelmachowski P, Maniak G, Kotarba A, Sojka Z (2009) Catal Commun 10:1062-1065

24. An H, McGinn PJ (2006) Appl Catal B 62:46-56

25. Gálvez ME, Ascaso S, Stelmachowski P, Legutko P, Kotarba A, Moliner R, Lázaro MJ (2014) Appl Catal B 152-153:88-98

26. Legutko P, Kaspera W, Stelmachowski P, Sojka Z, Kotarba A (2014) Catal Commun 56:139-142

27. Ura B, Trawczynski J, Kotarba A, Bieniasz W, Illan-Gomez MJ, Bueno-Lopez A, Lopez-Suarez FE (2011) Appl Catal B 101:169-175

28. Su C, McGinn PJ (2014) Catal Commun 43:1-5

29. Russel A, Epling WS (2011) Catal Rev 53:337-423

30. Stanmore BR, Brilhac JF, Gilot P (2001) Carbon 39:2247-2268

31. Atribak I, Bueno-Lopez A, Garcia-Garcia A, Navarro P, Frias D, Montes M (2010) Appl Catal B 93:267-273

32. Blangero M, Decourt R, Carlier D, Ceder G, Pollet M, Doumerc JP, Darriet J, Delmas C (2005) Inorg Chem 44:9299-9304

33. Miceli P, Bensaid S, Russo N, Fino D (2014) Nanoscale Res Lett 9:1-10

34. Piumetti M, Bensaid S, Russo N, Fino D (2015) Appl Catal B 165:742-751

35. Stelmachowski $P$, Legutko $P$, Jakubek T, Indyka $P$, Sojka Z, Holmlid L, Kotarba A (2015) Phys Chem Chem Phys 17:26289-26294

36. Julien C, Massot M, Rangan S, Lemal M, Guyomard D (2002) J Raman Spectrosc 33:223-228

37. Gao T, Glerup M, Krumeich F, Nesper R, Fjellvåg H, Norby $\mathrm{P}$ (2008) J Phys Chem C 112:13134-13140

38. Iyer A, Del-Pilar J, King'Ondu CK, Kissel E, Garces HF, Huang H, El-Sawy AM, Dutta PK, Suib SL (2012) J Phys Chem C 116:6474-6483

39. Kreisel J, Lucazeau G, Vincent H (1998) J Solid State Chem 137:127-137

40. Inger M, Wilk M, Saramok M, Grzybek G, Grodzka A, Stelmachowski P, Makowski W, Kotarba A, Sojka Z (2014) Ind Eng Chem Res 53:10335-10342

41. Lemmens P, Choi KY, Gnezdilov V, Sherman E, Chen D, Lin CT, Chou FC, Keimer B (2006) Phys Rev Lett 96:16720

42. Yamazaki K, Sakakibara Y, Dong F, Shinjoh H (2014) Appl Catal A 476:113-120

43. Jakubek T, Kaspera W, Legutko P, Stelmachowski P, Kotarba A (2015) Catal Commun 71:37-41

44. Bensaid S, Russo N (2011) Catal Today 176:417-423

45. Kumar A, Tanwar D, Bensaid S, Russo N, Fino D (2012) Chem Eng J 207:258-266 